\title{
Ringe tauschen
}

\section{Erhard Taverna}

Dr. med.

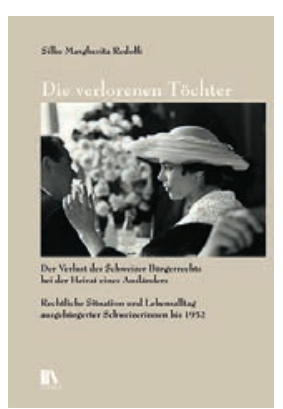

Silke Margherita Redolfi

Die verlorenen Töchter Der Verlust des Schweizer Bürgerrechts bei der Heirat eines Ausländers. Rechtliche Situation und Lebensalltag ausgebürgerter Schweizerinnen bis 1952

Chronos Verlag, 2019. ISBN 978-3-0340-1504-2
Wer in sehr bescheidenen Verhältnissen auf einem abgelegenen Höckli lebt, wird Mühe haben, eine Frau zu finden. TV-Staffeln wie Bauer, ledig, sucht ... gab es damals noch nicht, und die Mutter duldete keinen Fernseher im Haus. Dann starb sie, und ein Jahr danach kam er mit seiner Ehefrau in die Sprechstunde. Eine Filipina, im vierten Monat schwanger, beide leicht verwahrlost, aber anscheinend zufrieden. Der Pfarrer habe ihm mit Katalogen ausgeholfen, mit tschechischen Traumfrauen, Russinnen und Thailänderinnen. Bei allen Kontakten habe er ihn unterstützt, dann ging es plötzlich sehr schnell. Beide unterhielten sich in einer Art Zeichensprache mit vereinzelten englischen und appenzellischen Ausdrücken. Das genügte für ein Leben hinter den Hügeln. Sie sind immer noch zusammen.

Rund $10 \%$ aller verheirateten Personen leben in einer gemischt-nationalen Partnerschaft. In diesem Punkt ist die Schweiz in Europa führend. Mehr als ein Drittel aller Eheschliessungen werden mit einem ausländischen Partner eingegangen. Seit 1970 hat sich die Zahl auf 15118 Trauungen verdoppelt. Gemäss Bundesamt für Statistik haben 2009-2018 37333 Männer mit einem Schweizer Pass eine Ausländerin geheiratet, davon 1406 eine Frau aus den Philippinen.

\section{Rund $10 \%$ aller verheirateten Personen leben in einer gemischt-nationalen Partnerschaft.}

Die Bäuerin aus dem fernen Höckli ist längst eingebürgert, obwohl die Gesetze seit 1978 fünf Mal, allerdings im Sinne einer zunehmenden Öffnung, revidiert wurden. Gemäss einer Broschüre des Eidgenössischen Statistischen Amtes zur Landesausstellung von 1939 heiratete jeder achte Schweizer eine Ausländerin. Seit 1910 wurden 128000 neu eingebürgert, 78000 Ausländerinnen erhielten durch Heirat das Bürgerrecht. In der damaligen Situation sah die offizielle Schweiz darin eine staatspolitische Gefahr und damit eine Aufgabe der geistigen Landesverteidigung. «Können diese Frauen, wenn sie Mütter werden oder sind, unsere Jugend in gutem Schweizersinn erziehen ... auch wenn die Hälfte in unserem Lande geboren wurde, hier die Schule besuchte, also mit unserem Volkstum einigermassen verwachsen ist?» «1910-1937 heirateten 32000 Schweizertöchter einen bei uns wohnenden Ausländer. Durch Elternhaus, Freunde und Verwandte im angestammten Volk verankert, werden sie ihr schweizerisches Erb-

\section{Die Heirat mit einem Ausländer führte zu einem faktischen Berufsverbot.}

gut auch im neuen Milieu treu verwalten.» Trotzdem verschärfte die Schweiz 1941 per Notrecht die Heiratsregeln für Schweizerinnen, die einen Ausländer ehelichten. Die Historikerin Silke Margherita Redolfi beschreibt in ihrem Buch Die verlorenen Töchter, wie viele dieser Frauen der Ämterwillkür ausgeliefert waren, denn Niederlassung und Aufenthalt waren an die Staatsangehörigkeit der Männer geknüpft. Tausende verloren ihre Bürgerrechte mit fatalen Folgen. Sie mussten bis 1952 ihren Pass abgeben, was im Falle von Armut oder Krankheit zur Ausschaffung führen konnte. Auch wer nicht weiter auffiel und vor allem keine Sozialkosten verursachte, konnte geächtet und diskriminiert werden. Etwa eine Medizinstudentin, die nach der Heirat mit einem Franzosen als Ausländerin nicht mehr zu den Prüfungen zugelassen war. Wer als Juristin, Polizistin oder Fürsorgerin arbeiten wollte, brauchte das Schweizer Bürgerrecht. Lehrerinnen mussten den Schuldienst aufgeben. Die Heirat mit einem Ausländer führte zu einem faktischen Berufsverbot. Für Verwitwete oder Geschiedene war eine Wiedereinbürgerung möglich. Allerdings ohne rechtlichen Anspruch. Der Bundesrat bezeichnete diese Massnahme als «Rechtswohltat.» Diese Heiratsregel machte Schweizerinnen zu Fremden im eigenen Land. Ein prominentes Beispiel ist die Künstlerin Sophie Taeuber, die das Bürgerrecht verlor, als sie den Deutsch-Franzosen Hans Arp heiratete. Mangelernährt im besetzten Frankreich, erhielt sie Lebensmittelpakete aus der Heimat. Wer das Bürgerrecht verlor, konnte keinen diplomatischen Schutz der Schweiz beanspruchen. 